\title{
Właściwości napawanych warstw Fe-Cr-C-Nb przy zastosowaniu kierunkowego odbioru ciepła
}

\author{
Properties of the deposited layers of Fe-Cr-Nb-C \\ by using directional receiving heat
}

\section{Streszczenie}

W pracy przedstawiono wyniki badań nad napoinami trudnościeralnymi przeznaczonymi do pracy w warunkach intensywnego zużycia ściernego. Głównym celem pracy była analiza własności przy wykorzystaniu drutu dającego twardości sięgające do 1200 HV1 warstwy wierzchniej w jednym przejściu. Do zwiększenia szybkości odprowadzenia ciepła z miejsca napawania zastosowano blachy aluminiowe. Próbki napawane poddano badaniu rozkładu twardości wraz z identyfikacją miejsca pomiaru oraz badaniom metalograficznym na mikroskopie optycznym i mikroskopie skaningowym z mikroanalizą rentgenowską. Zastosowanie płyt zwiększających odbiór ciepła z miejsca napawania pozwoliło na zwiększenie twardości $\mathrm{w}$ warstwie napoiny tuż nad linią wtopienia.

Słowa kluczowe: napoiny trudnościeralne; drut proszkowy; Fe-Cr-C-Nb; SEM; FCAW

\begin{abstract}
The paper presents results of research on surface hard wearing designed to work in the conditions of intense abrasive wear. The main objective of the study was to perform influence the directional reception heat of using a wire giving a hight hardness surface layer (up to $1200 \mathrm{HV} 1$ ) in a single pass bead. To increase the speed of heat dissipation from the place of hardfacing a sheet of aluminum was used. The samples were examined hardness distribution together with the identification of the place of measurement and testing metallographic optical microscope (OM) and scanning electron microscope (SEM) with X-ray EDS. The use of aluminum sheet to increase the heat transfer from the space surfacing allowed to increase the hardness of the deposit in a layer just above the line of fusion.
\end{abstract}

Keywords: hardfacing; cored wire; Fe-Cr-C-Nb; SEM; FCAW

\section{Wstęp}

Postęp w inżynierii materiałowej, metalurgii i spawalnictwie zapewnia możliwość stosowania coraz doskonalszych materiałów metalowych, które są w stanie przenosić coraz to wyższe parametry pracy oraz zwiększać trwałość części maszyn i urządzeń. Aby wykorzystać właściwości tych materiałów, problem zużycia musi być uwzględniony na etapie projektowania, wytwarzania i eksploatacji maszyn. Najbardziej efektywnym sposobem przeciwdziałania zużyciu jest wykonywanie powierzchni roboczych technologiami spawalniczymi z materiałów o specjalnych własnościach. Jednym z takich procesów jest napawanie prewencyjne, stosowane w celu zabezpieczenia np. płyt przesypowych, czy też płyt bocznych taśmociągów wykorzystywanych szczególnie w przemyśle wydobywczym. W procesie wydobywania węgla brunatnego metodą odkrywkową, czynnością konieczną do jego urabiania, jest usunięcie mas ziemnych i skalnych zalegających nad jego podkładem tzw. nadkładu. W tym celu stosowany jest układ technologiczny, w którego skład wchodzi koparka kołowa, przenośnik taśmowy oraz zwałowarka. Ogromna ilość mas ziemnych podlegających procesowi urabiania powoduje konieczność zastosowania części o bardzo dużej odporności na ścieranie. W celu ograniczenia zużycia, elementy układu poddaje się procesowi napawania wysokochromowymi stopiwami o strukturze żeliw chromowych. Stopy tworzące żeliwo chromowe posiadają bardzo wysoką odporność na ścieranie, przy umiarkowanej odporności udarowej oraz korzystnym stosunku ceny do jakości. Dobra odporność na ścieranie jest możliwa dzięki obecności licznych węglików w stosunkowo miękkiej osnowie. Badania mikrostruktury napoin wysokochromowych wykonywanych różnymi metodami spawalniczymi wskazują, że są to najczęściej węgliki złożone typu ( $\mathrm{Cr}, \mathrm{Fe}) 3 \mathrm{C}$, (Cr,Fe)7C3, (Cr,Fe)23C6, NbC, Nb2C w zależności od składu chemicznego użytego materiału dodatkowego do napawania.

Dr inż. Robert Bęczkowski - Politechnika Częstochowska; dr inż. Janusz Cebulski; mgr inż. Dorota Pasek - Politechnika Śląska.

Autor korespondencyjny/Corresponding author. rbeczkowski@spaw.pcz.pl 
Należy zaznaczyć, że nadmierny wzrost twardości napoiny powoduje wzrost zużycia ścierno-udarowego. Jest on wynikiem spadku trwałości kontaktowej warstwy napawanej z powierzchnią zabezpieczaną, a w konsekwencji prowadzi do jej wykruszania.

Największy udział w zużyciu elementów jest wynikiem zużycia ściernego i stanowi około $50 \%$ wszystkich ubytków. Wypadkową zużycia jest zespół czynników, z których najważniejsze przedstawiono w postaci diagramu Ischikawy (rys. 1).

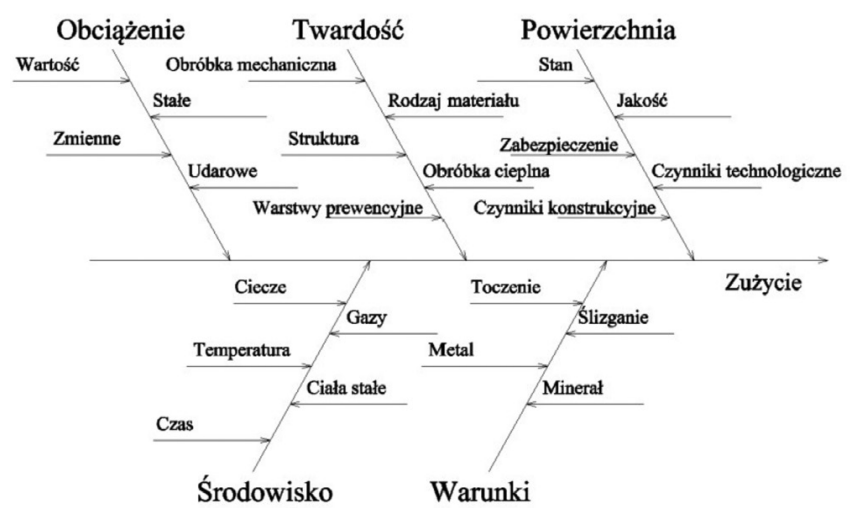

Rys. 1. Czynniki wpływające na zużycie

Fig. 1. Factors which have an affect on wear

Analizując warunki pracy i zużycia, poszukujemy wszelkiego rodzaju czynników, które dają możliwość poprawy trwałości części maszyn i urządzeń.

O metodach i technologiach mogących mieć zastosowanie w zakresie zabezpieczenia powierzchni przed zużyciem decydują uwarunkowania techniczne, użytkowe oraz ekonomiczne poszczególnych części maszyn lub urządzeń.

Pracujące urządzenia są narażone na czynniki powodujące zużycie różnego typu. Jednakże do wydłużenia okresu eksploatacji lub przywróceniu funkcjonalności poszczególnych elementów stosuje się różne technologie spawalnicze. Do uzyskiwania kilku milimetrowych warstw zabezpieczających najpowszechniejsze jest napawanie z wykorzystaniem drutów rdzeniowych.

W zależności od warunków pracy stosuje się określone zasady, jakimi należy się kierować przy wyborze materiału dodatkowego i metody regeneracji, czy prewencji, tak by podjęte działania były zarówno uzasadnione technologicznie, jak i ekonomicznie.

Poprawiając trwałość elementów maszyn pracujących w warunkach narażonych na ścieranie typu metal-minerał, stosujemy napawanie prewencyjne bądź technologiczne, wykorzystując materiały dające napoiny odporne na zużycie, zawierające węgliki z fazami o twardości powyżej 1000 HV w warstwach wierzchnich napoiny.

Trwałość powierzchni zwiększamy stosując wszelkiego rodzaju blachy kompozytowe, napawanie prewencyjne oraz regeneracyjne $z$ wykorzystaniem materiałów dodatkowych pozwalających uzyskać struktury z twardymi wydzieleniami węglików $\mathrm{Cr}, \mathrm{V}, \mathrm{W}, \mathrm{Nb}, \mathrm{Ti}, \mathrm{B}$.

$\mathrm{Na}$ podstawie analizy literatury można stwierdzić, że nowoczesne materiały dodatkowe do napawania w postaci drutów rdzeniowych na stałe wpisują się do przemysłu. $[1 \div 13]$.

\section{Metodyka badań}

Do przygotowania prób wykorzystano automat do napawania wyposażony w stół chłodzony wodą wyłożony płytami aluminiowymi poprawiającymi odprowadzenie ciepła z miejsca napawania. Do prób napawania użyto materiału podstawowego gatunku S235JR o grubości $10 \mathrm{~mm}$ i wymiarach pojedynczej płyty $200 \times 400 \mathrm{~mm}$. Do napawania użyto drutu o składzie chemicznym ( $\mathrm{C}=5,4 \%, \mathrm{Cr}=29 \%, \mathrm{Si}=1,2 \%$, $\mathrm{Nb}=3,0 \%, \mathrm{Mn}=0,4 \%, \mathrm{~B}<1 \%$ ). Jako wielkości wejściowe zostały określone: prędkość napawania, (160 mm/min), współczynnik przewodzenia dla aluminium, $(2,15 \mathrm{~W} / \mathrm{mK})$, ustawienia mocy źródła, (11480 W), długość wystającego odcinka elektrody, (30 mm), prędkość oscylacji $(2,4 \mathrm{~m} / \mathrm{min})$, prędkość podawania drut $(5,8 \mathrm{~m} / \mathrm{min})$, średnica drutu (2,8 mm) szerokość amplitudy zakosów (35 mm), pozycja napawania PA.

Próbki zostały wykonane z napoiną o średniej grubości $5 \mathrm{~mm}$. Następnie przygotowane próbki poddano badaniom twardości na przekroju napoiny. Analizowano zależność twardości od odległość od lica napoiny. Badania przeprowadzono metodą Vickersa zgodnie z wymaganiami PN EN ISO 6507-1 przy obciążeniu 9,81N (HV1) na urządzeniu typu ZWICK.

Próbki po polerowaniu i trawieniu nitalem zostały poddane badaniom na mikroskopie optycznym typu Olympus GX51. Próbki poddane zostały również analizie na skaningowym mikroskopie elektronowym wraz z mikroanalizą rentgenowską EDS na urządzeniu typu Hitachi S4200.

\section{Analiza wyników}

Pomiary twardości wykonano zgodnie ze schematem przedstawionym na rysunku 2 . Twardość mierzono w układzie prostopadłym do powierzchni przedstawionym jako linie (ML1, ML2, ML3). Rozkład twardości w funkcji położenia przedstawiono na rysunku 2.

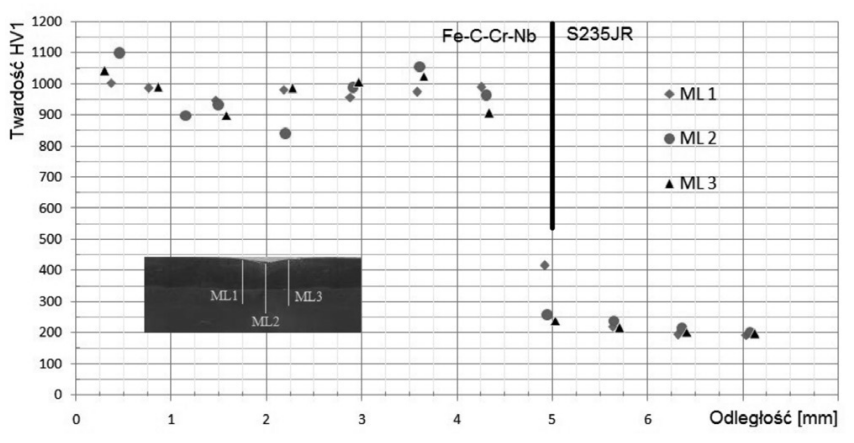

Rys. 2. Rozkład twardości z uwzględnieniem odległości od powierzchni roboczej napoiny

Fig. 2. Hardness distribution of the distance from the work surface of the bead

Obserwuje się twardości sięgające 1100 HV1 w obszarze górnej warstwy napoiny. W środkowej części twardość nieznacznie spada do wartości 850-900 HV1, by w warstwie tuż nad linią wtopienia osiągnąć wartości dochodzące do 1050 HV1 w odległości 3-4 mm od powierzchni próbki.

$\mathrm{Na}$ podstawie obserwacji na mikroskopie optycznym przeanalizowano cztery obszary napoiny: górę, środek, dół i linię wtopienia. Wyniki obserwacji zostały pokazane na rysunku 3. Przedstawiono widok napoiny przy powiększeniu obrazu 1000x dla górnej warstwy napoiny - odległość od lica do $1 \mathrm{~mm}$ (rys. 3a), warstwy środkowej - odległość od lica od 1 do $3 \mathrm{~mm}$ (rys. 3b), warstwy nad linią wtopienia - odległość od lica od 3 do 4,5 mm (rys. 3c) oraz obraz linii wtopienia (rys. 3d).

W obszarach o podwyższonej twardości (góra i dół napoiny rys. 3a i 3c) obserwuje się więcej wydzieleń związków niobu. W obszarze środkowym (rys. 3b) widoczne są większe wydzielenia węglików chromu i mniejszy udział węglików niobu niż w obszarach u góry oraz w dolnych warstwach napoiny. Analizy dokonano na podstawie analizy SEM. 

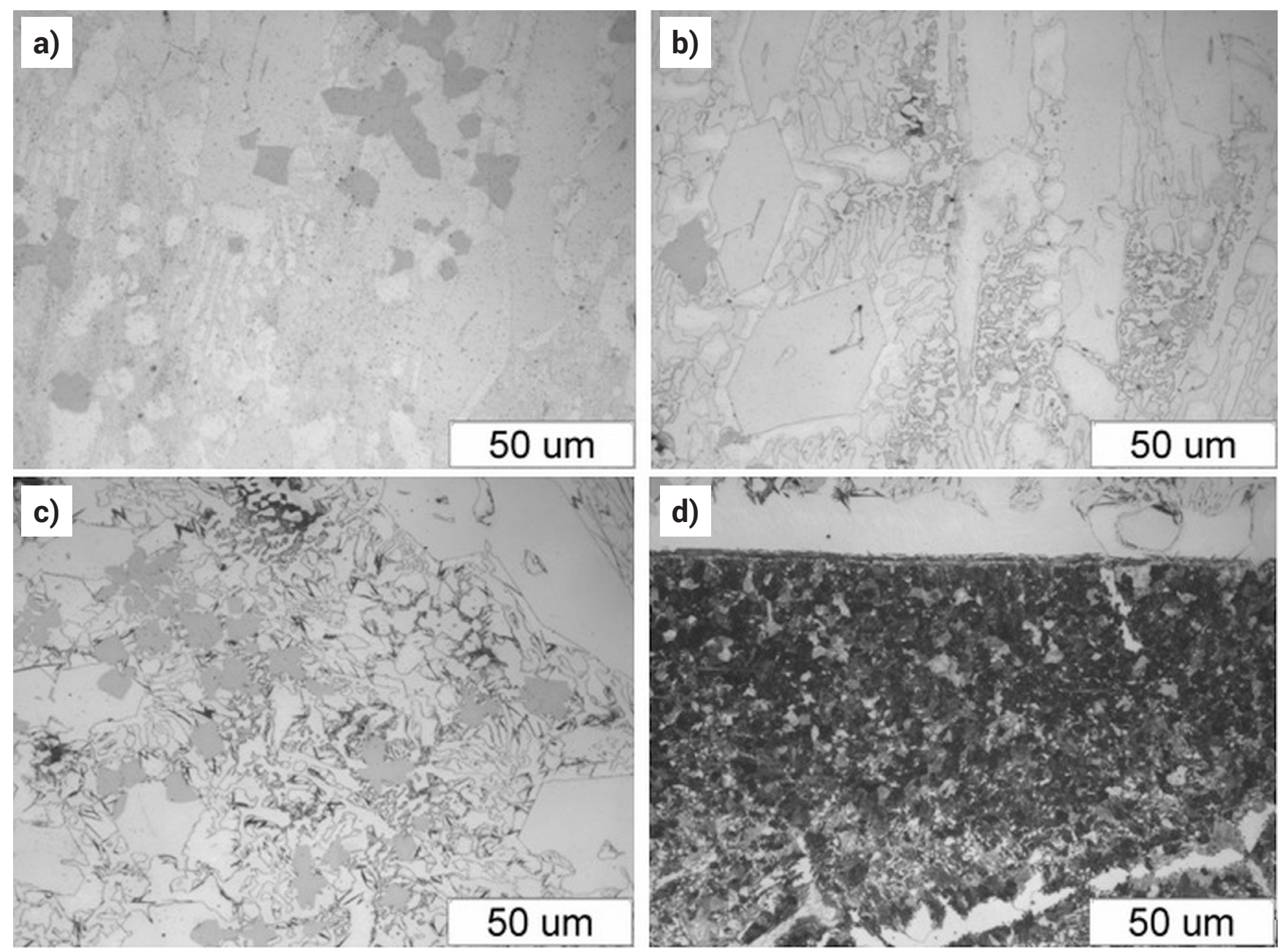

Rys. 3. Struktura napoiny z rozkładem węglików

Fig. 3. Structure of bead with distribution of the carbides

Obserwacje powierzchni warstw napawanych oraz mikroanalizę rentgenowską składu chemicznego wykonano za pomocą elektronowego mikroskopu skaningowego HITACHI S4200 wyposażonego w detektor promieniowania rentgenowskiego składu chemicznego EDS. Wykazano, że warstwa trudnościeralna zawiera takie pierwiastki jak: Fe, $\mathrm{Cr}$, Nb i C. Biorąc pod uwagę powinowactwo chemiczne tych pierwiastków można przyjąć, że w materiale najprawdopodob-

Tablica I. Zawartość wagowa pierwiastków Table I. Chemical composition, weight \%

\begin{tabular}{|c|c|c|c|c|c|c|}
\hline & $\mathrm{C}$ & $\mathrm{Si}$ & $\mathrm{Ti}$ & $\mathrm{Cr}$ & $\mathrm{Fe}$ & $\mathrm{Nb}$ \\
\hline Base(4)_pt1 & 2,8 & & 1,3 & 1,9 & 2,3 & 91,6 \\
\hline Base(4)_pt2 & 1,5 & & & 25,0 & 73,5 & \\
\hline Base(4)_pt3 & & 1,6 & & 5,7 & 92,7 & \\
\hline
\end{tabular}

Tablica II. Zawartość atomowa pierwiastków Table II. Chemical composition, atom \%

\begin{tabular}{|c|c|c|c|c|c|c|}
\hline & $\mathrm{C}$ & $\mathrm{Si}$ & $\mathrm{Ti}$ & $\mathrm{Cr}$ & $\mathrm{Fe}$ & $\mathrm{Nb}$ \\
\hline Base(4)_pt1 & 17,7 & & 2,1 & 2,8 & 3,1 & 74,3 \\
\hline Base(4)_pt2 & 6,5 & & & 25,0 & 68,4 & \\
\hline Base(4)_pt3 & & 3,1 & & 6,0 & 90,9 & \\
\hline
\end{tabular}

niej występują węgliki niobu i chromu (rys. 4). Ze względu na przyjętą metodykę badawczą, udział węgla należy traktować szacunkowo. Tablica I przedstawia zawartości wagowe pierwiastków, a tablica II zawartości atomowe pierwiastków.
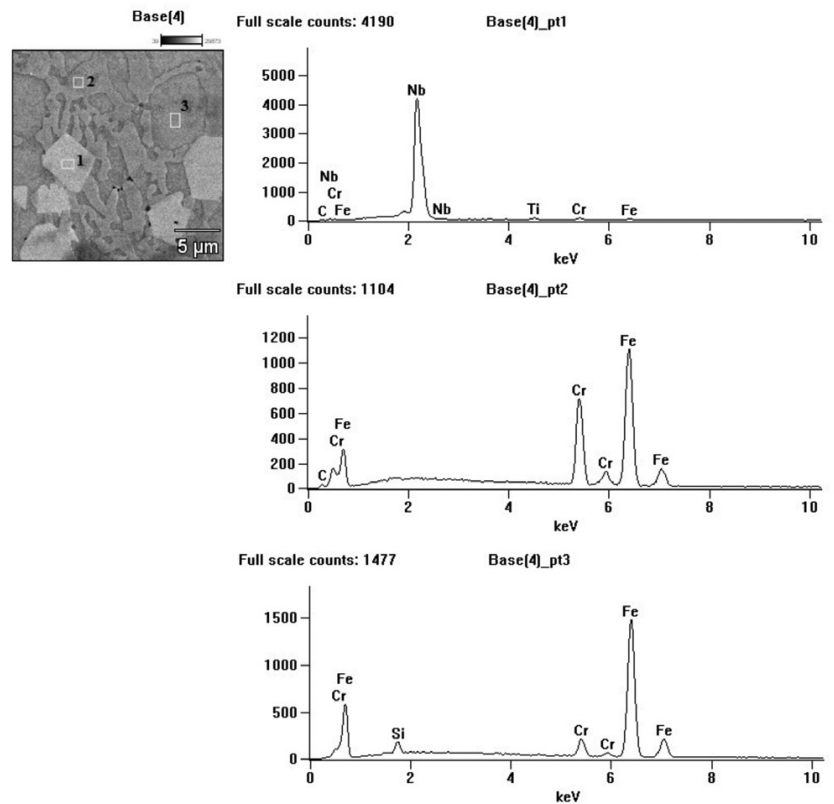

Rys. 4. Analiza SEM wraz z identyfikacją chemiczna

Fig. 4. SEM analysis of the microscope together with an indication of the chemical composition 


\section{Wnioski}

Wpływ zastosowania do odbioru ciepła płyt aluminiowych na rozkład twardości daje informację, iż w warstwie napoiny od strony lica jest najwyższa twardość, stopniowo malejąc w środkowej części, by ponownie wzrastać w obszarze linii wtopienia, co może być spowodowane zwiększonym odbiorem ciepła.

Obserwowane struktury na mikroskopie optycznym pokazują, iż główne kierunki osi węglików są ułożone zgodnie z kierunkiem odbioru ciepła. Rozmieszczenie węglików niobu jest nieregularne. Zidentyfikowano obszary o niewielkiej zawartości niobu, jak i obszary o dużym nasyceniu w ten pierwiastek. Nie można jednoznacznie określić przyczyny takiej sytuacji.

Badania wykonane przy użyciu elektronowego mikroskopu skaningowego wraz z mikroanalizą rentgenowską składu chemicznego pozwalają stwierdzić, że napawana warstwa trudnościeralna charakteryzuje się budową złożoną (wielofazową) składającą się z osnowy oraz węglików chromu i niobu o zróżnicowanej morfologii.

\section{Literatura}

[1] Adamiak, M., Górka, J., Kik, T.: Structure analysis of welded joints of wear resistant plate and constructional steel, Archives of Materials Science and Engineering, (2010) 56, 2, 108-114

[2] Bęczkowski, R.: Effect of cladding parameters on the hardness of bimetal plates. Metalurgija, (2017) 56, 1-2, 59-62.

[3] Bęczkowski, R., Gucwa, M., Wróbel, J., and Kulawik, A.: The impact of the bead width on the properties of the anti abrasion surfacing weld. International Conference of Numerical Analysis and Applied Mathematics 2015 (ICNAAM 2015), (2015) AIP Conf. Proc. 1738, 480095-1-480095-4; doi: 10.1063/1.4952331.

[4] Bęczkowski, R., Gucwa, M.: Defects Appearing in the Surfacing Layers of Abrasion Resistant, Archives of Foundry Engineering, (2016) 16,4, 23-28.

[5] Bęczkowski, R., Gucwa, M.: Kwalifikowanie napawania warstw trudnościeralnych pracujących w warunkach przemysłu cementowego, Przegląd Spawalnictwa, (2015) 9, 43-46.

[6] Dwivedi, D.,K.: Microstructure and abrasive wear behaviour of iron base hardfacing, Materials Science and Technology, (2004) 20, 1326-1330

[7] Gucwa, M., Bęczkowski, R.: Odporność na erozyjne zużycie strumieniowe napoin wykonanych drutem proszkowym samoosłonowym przy kącie padania ścierniwa 60o, Przegląd Spawalnictwa, (2011) 10,77-80
[8] Kejžar R.: Study of the alloying of a surfacing weld in the surfacing of wear-resistant deposits with alloyed welding fluxes. Materials and technology, (2003) 37, 3-4, 167-172.

[9] Mendez, P.F., Barnes, N., Bell, K., Borle, S.D., Gajapathi, S. S., Guest, S. D., Izadi, H., Gol, A. K., Wood, G.: Welding processes for wear resistant overlays. Journal of Manufacturing Processes, (2014) 16, 4-25.

[10] Niagaj, J.: Effect of niobium on properties of hardfaced layers surface welded by Fe-Cr-C open arc flux-cored wire electrodes, Welding Technology Review, (2011) 10, 67-72.

[11] Orłowicz, W., Shevelyaa, V., Trytek, A., V. Kirilkov, V.: Effect of the concentrated heat flow treatment on the structure and the antiwear properties of cast iron, Archives of Foundry Engineering, (2009) 9, 2, 185-188

[12] Pernis, I., Kasala, J., Žabecká, D.: (2013) Resistance of weldclads made by flux-cored arc welding technology against erosive wear. Metalurgija, $52,3,352-354$.

[13] Winczek, J.: (2016) Modeling of heat affected zone in multipass GMAW surfacing S235 steel element. Procedia Engineering, 136, 108 - 113. 